\title{
OPTIMASI DIAMETER JARINGAN PIPA DALAM SISTEM PENYEDIAAN AIR BERSIH (PDAM) DI KEC. BULULAWANG KAB. MALANG MENGGUNAKAN LINEAR PROGRAMMING
}

\author{
Optimization of Networking Pipe in Water Supply Sistem (PDAM) in Bululawang, Malang \\ Using Linear Programming \\ Chairil Saleh $^{1}$, Frica Anandy ${ }^{2}$ \\ ${ }^{\mathbf{1 , 2 3}}$ Program Studi Teknik Sipil, Fakulas Teknik, Universitas Muhammadiyah Malang \\ Jalan Raya Tlogomas No. 246 Malang 65144 \\ Alamat Korespondensi: \\ Email: Frica.anandy@yahoo.co.id
}

\begin{abstract}
One of the most important roles of water system supply is piping networking. Performance of water supply sistem service is determined not only by a capacity from the source, but also by water volume which must also be up to the vertices with high flow and adequate pressure as needed. Besides, the effectiveness of a pipline is measured from the cost of investment and operational cost over life of specified order. In order to achieve adequate pressure and flow conditions it must be analyzed the size carefully. Linear programming represents the completion of operations research techniques that can solve optimization problems. Linear prograsmming is used to minimize cost size of pipe. On this research, a sample informartion taken by a clean water distributin network in sub-district of Bululawang, district of Malang. By using the method of linear programing the result of optimization in diameter on each pipe in sub-district of Bululawang, district of Malang with the selection of the main pipe diameter between 3 inch to 8 inch and pressure energy or relative energy is 7 metes into 20 metes by license set.
\end{abstract}

Keywords : Pipe Size, Relative Energy, Pipe Networking, Linear Programming, Optimization

\begin{abstract}
Abstrak
Salah satu peran penting dari sistem penyediaan air bersih adalah jaringan perpipaan. Kinerja pelayanan sistem penyediaan air bersih tidak hanya ditentukan oleh besarnya kapasitas sumber, namun volume air tersebut juga harus sampai pada simpul-simpul layanan dengan aliran dan tinggi tekanan yang memadai sesuai kebutuhan. Disamping itu efektivitas sebuah jaringan pipa juga dapat diukur dari besarnya biaya investasi dan operasionalnya selama usia guna yang ditetapkan. Agar dicapai kondisi tekanan dan debit yang memadai, perlu dilakukan analisis diameter yang cermat. Linear programing merupakan satu teknik penyelesaian riset operasi yang dapat menyelesaikan masalah-masalah optimasi. linear programming digunakan untuk meminimasi biaya akibat pemakaian diameter pipa. Pada penelitian ini diambil sampel data jaringan pipa distribusi air bersih di Kec.Bululawang Kab.Malang. Dengan metode linear programing didapat hasil optimasi diameter pada masing-masing pipa di Kec. Bululawang Kab. Malang dengan pemilihan diameter pipa utama antara 3 inch sampai 8 inch dan energi tekan atau energy relatif yang dihasilkan adalah 7 meter sampai 20 meter sesuai standart ijin yang ditetapkan.
\end{abstract}

Kata Kunci : Diameter pipa, Energi tekan, Jaringan pipa, Linear Programming, Optimasi,

\section{PENDAHULUAN}

Air bersih merupakan salah satu kebutuhan yang paling utama bagi hidup manusia. Tidak tersedianya air bersih akan berdampak pada keseimbangan hidup manusia. Salah satu peran penting dari sistem penyediaan air bersih adalah jaringan perpipaan. Karena tingkat efektifitas jaringan 
pipa merupakan salah satu factor penentu besarnya kinerja pada sistem penyediaan air bersih.

Kinerja pelayanan sistem penyediaan air bersih tidak hanya ditentukan oleh besarnya kapasitas sumber, namun volume air tersebut juga harus sampai pada simpul-simpul layanan dengan aliran dan tinggi tekanan yang memadai sesuai kebutuhan. Disamping itu efektivitas sebuah jaringan pipa juga dapat diukur dari besarnya biaya investasi dan operasionalnya selama usia guna yang ditetapkan. Upaya menemukan diameter pipa optimal yang menghasilkan kinerja sistim jaringan yang memuaskan hanya dapat ditentukan melalui teknik optimasi yang memiliki dua fungsi tujuan sekaligus, yaitu ;minimasi biaya investasi jaringan dan minimasi beda nilai tinggi energi relatif pada setiap simpul layanan (Sulianto, 2015).

Agar dicapai kondisi tekanan dan debit yang memadai, perlu dilakukan analisis diameter yang cermat. Penentuan diameter secara manual akan memakan waktu dan tenaga. Linear Programing merupakan salah satu metode optimasi yang sederhana namun cukup popular, karena sangat mudah dipahami. Penelitian ini dimaksudkan untuk memanfaatkan linear program untuk optimasi diameter pipa pada sistem jaringan pipa distribusi air bersih di Kec. Bululawang Kab. Malang.

\section{METODE PENELITIAN}

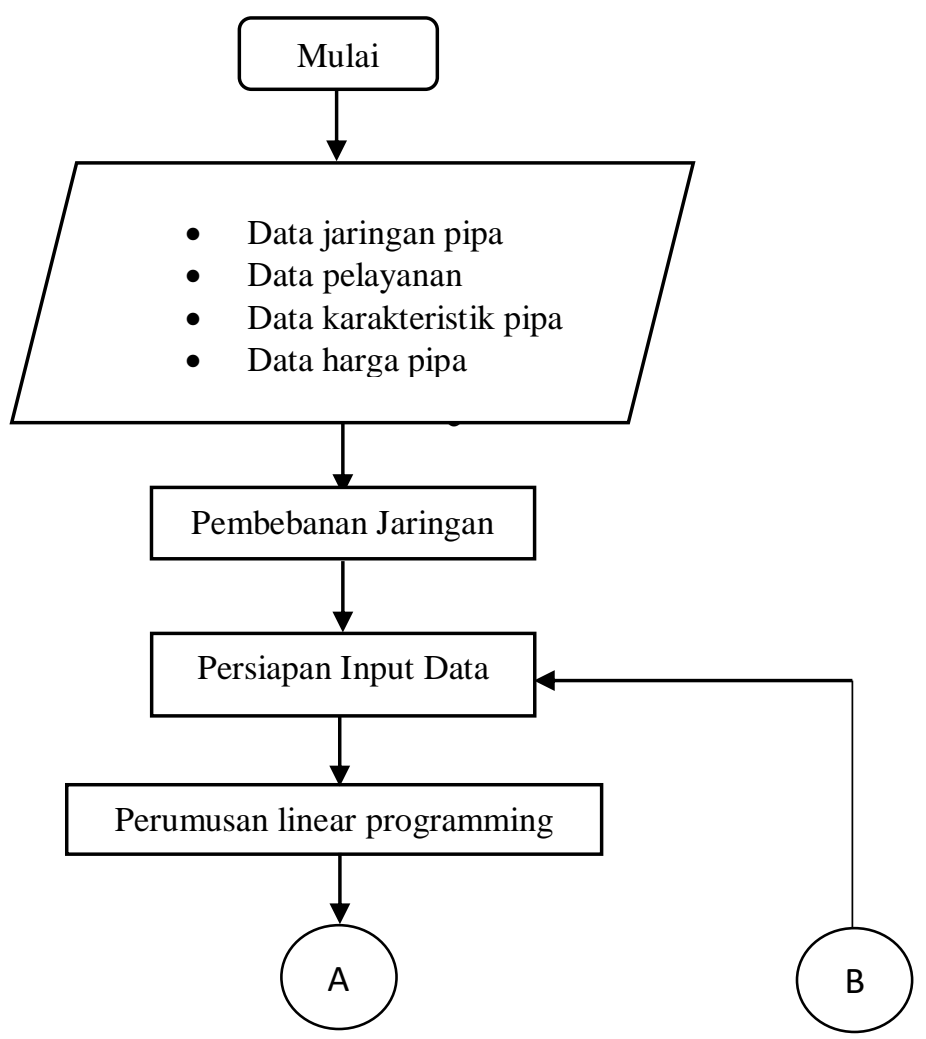




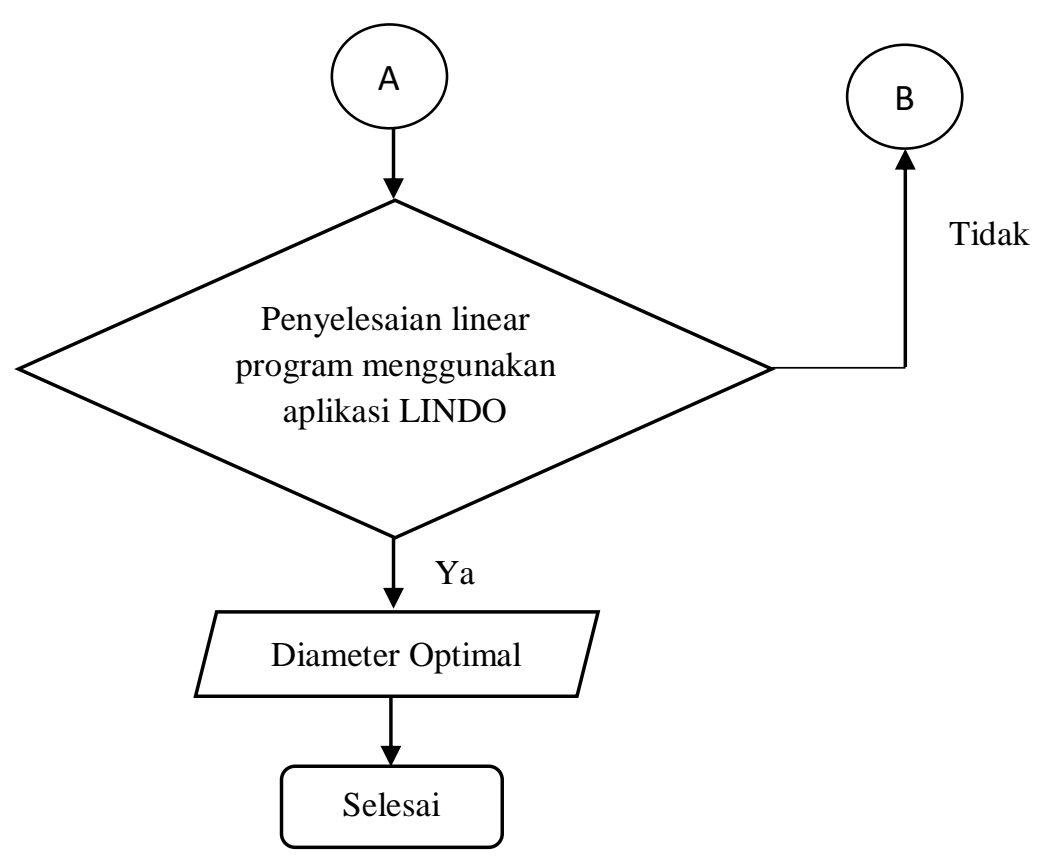

Gambar 1. Skema Tahapan Studi

\section{HASIL DAN PEMBAHASAN}

\section{Penyederhanaan Jaringan}

Penyederhanaan jaringan dilakukan karena mengingat bahwa aplikasi LINDO yang dimiliki bukan aplikasi LINDO Premium dimana aplikasi ini hanya mampu menyelesaikan dibawah 300 interasi. Sedangkan keseluruhan dari jaringan pipa di Kec. Bululawang sendiri terdapat lebih dari 100 node dan kandiat pipa yang digunakan sebanyak 5 jenis. Sehingga jumlah interasi yang dilakukan diperkirakan sejumlah \pm 500 interasi. Berikut hasil penyederhanaan jaringan:

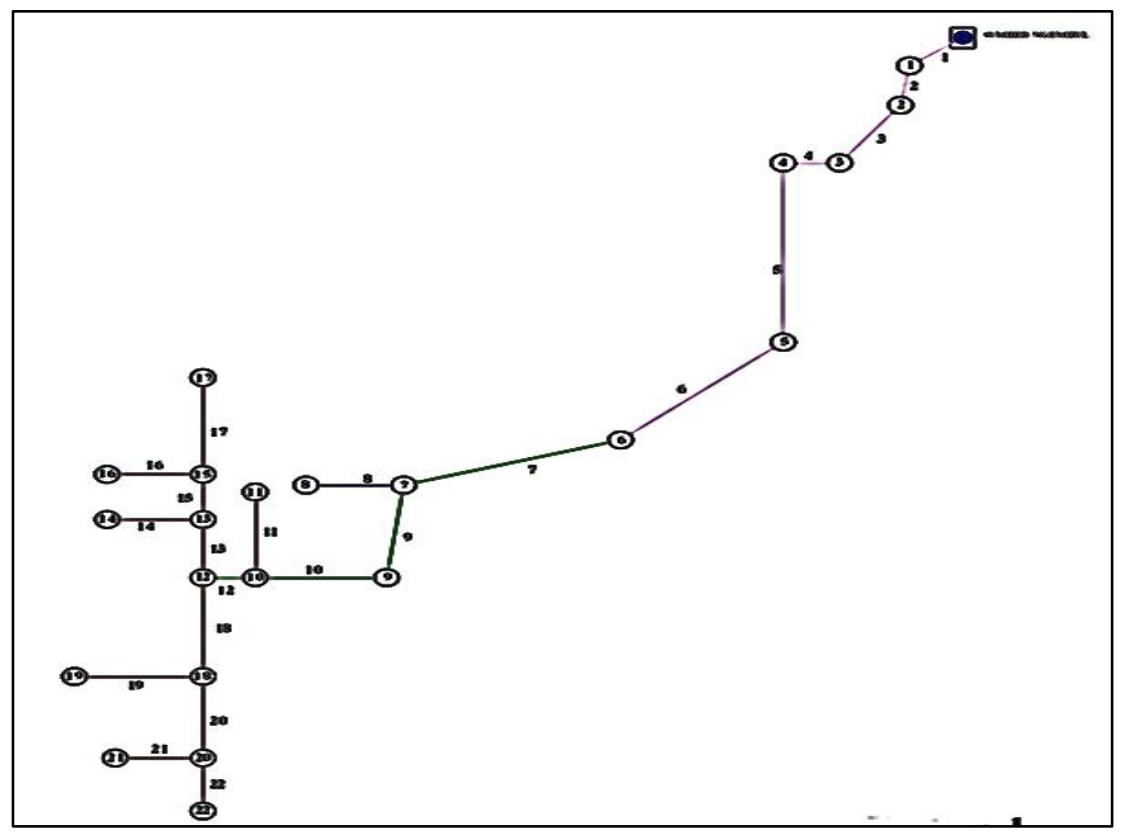

Gambar 2. Jaringan Pipa 1 


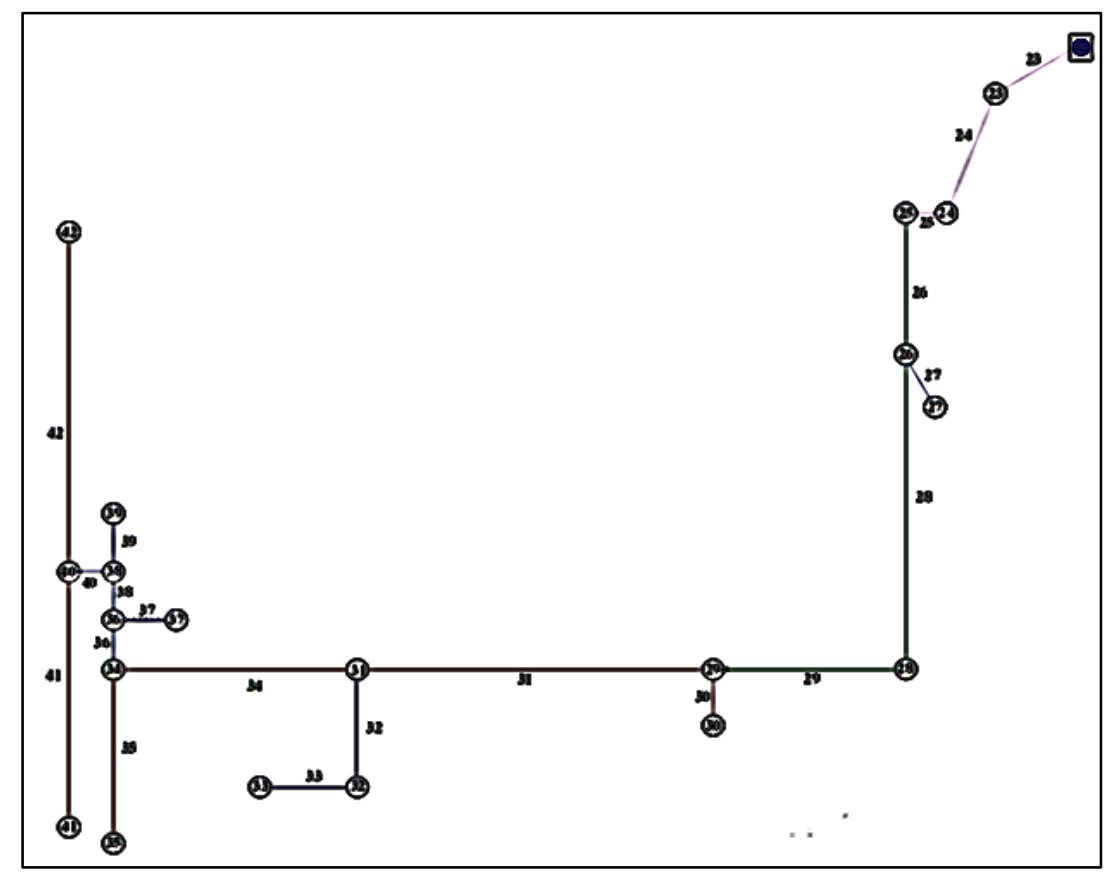

Gambar 3. Jaringan Pipa 2

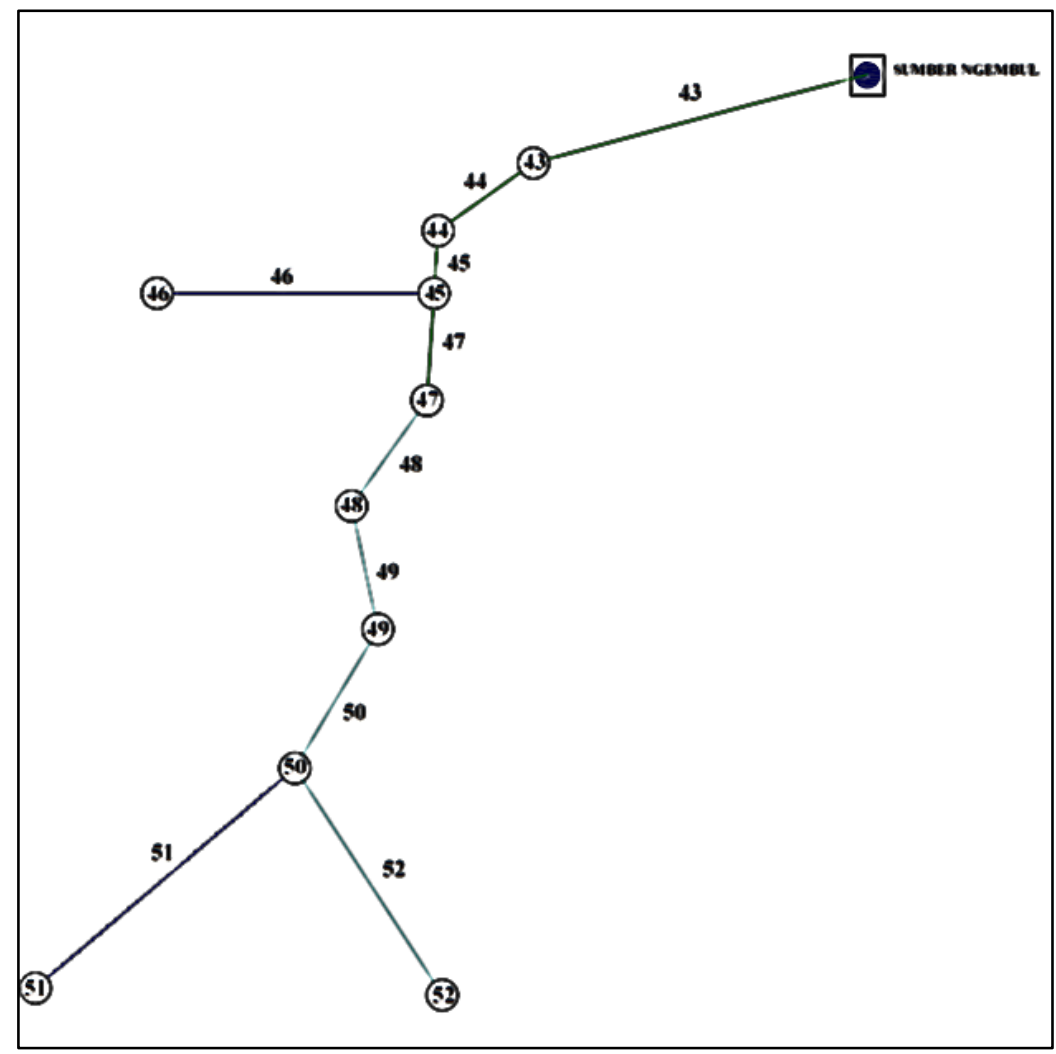

Gambar 4. Jaringan Pipa 3

\section{Pembebanan jaringan}

Pembebanan jaringan yang dimaksud adalah kebutuhan air (debit) setiap simpul layanan. Debit sendiri digunakan menyiapkan input data yaitu nilai kehilangan energi pada setiap nomer pipa. Berdasarkan data layanan (sambungan) pada sistem distribusi air bersih di Kec. Bululawang, maka diperoleh nilai 
debit jam puncak pada setiap pipa sebagai berikut:

Tabel 1. Kebutuhan air bersih masing-masing titik simpul pada jaringan pipa 1

\begin{tabular}{|c|c|c|c|c|c|}
\hline \multirow{3}{*}{ No Pipa } & \multirow{2}{*}{\multicolumn{2}{|c|}{ Node }} & \multirow{2}{*}{\multicolumn{2}{|c|}{$\begin{array}{c}\text { Debit }(\mathrm{Q}) \\
\text { Total }\end{array}$}} & \multirow{3}{*}{$\begin{array}{c}\text { Debit (Q) } \\
\text { Jam Puncak } \\
\text { (lt/dt) }\end{array}$} \\
\hline & & & & & \\
\hline & Dari & $\mathrm{Ke}$ & (lt/hr) & $(\mathrm{lt} / \mathrm{dt})$ & \\
\hline 1 & SB & 1 & 829450 & 9,600 & 14,400 \\
\hline 2 & 1 & 2 & 822950 & 9,525 & 14,287 \\
\hline 3 & 2 & 3 & 827950 & 9,583 & 14,374 \\
\hline 4 & 3 & 4 & 824950 & 9,548 & 14,322 \\
\hline 5 & 4 & 5 & 803700 & 9,302 & 13,953 \\
\hline 6 & 5 & 6 & 797700 & 9,233 & 13,849 \\
\hline 7 & 6 & 7 & 791700 & 9,163 & 13,745 \\
\hline 8 & 7 & 8 & 81000 & 0,938 & 1,406 \\
\hline 9 & 7 & 9 & 684950 & 7,928 & 11,891 \\
\hline 10 & 9 & 10 & 580800 & 6,722 & 10,083 \\
\hline 11 & 10 & 11 & 93750 & 1,085 & 1,628 \\
\hline 12 & 10 & 12 & 409300 & 4,737 & 7,106 \\
\hline 13 & 12 & 13 & 237750 & 2,752 & 4,128 \\
\hline 14 & 13 & 14 & 62500 & 0,723 & 1,085 \\
\hline 15 & 13 & 15 & 175250 & 2,028 & 3,043 \\
\hline 16 & 15 & 16 & 90500 & 1,047 & 1,571 \\
\hline 17 & 15 & 17 & 84750 & 0,981 & 1,471 \\
\hline 18 & 12 & 18 & 155800 & 1,803 & 2,705 \\
\hline 19 & 18 & 19 & 45000 & 0,521 & 0,781 \\
\hline 20 & 18 & 20 & 81100 & 0,939 & 1,408 \\
\hline 21 & 20 & 21 & 45750 & 0,530 & 0,794 \\
\hline 22 & 20 & 22 & 15750 & 0,182 & 0,273 \\
\hline
\end{tabular}

Sumber : Analisa dan Perhitungan

Tabel 2. Kebutuhan air bersih masing-masing titik simpul pada jaringan pipa 2

\begin{tabular}{|c|c|c|c|c|c|}
\hline \multirow{3}{*}{ No Pipa } & \multirow{2}{*}{\multicolumn{2}{|c|}{ Node }} & \multicolumn{2}{|c|}{ Debit (Q) } & \multirow{3}{*}{$\begin{array}{c}\text { Debit (Q) } \\
\text { Jam Puncak } \\
(\mathrm{lt} / \mathrm{dt})\end{array}$} \\
\hline & & & \multicolumn{2}{|c|}{ Total } & \\
\hline & Dari & $\mathrm{Ke}$ & (lt/hr) & (lt/dt) & \\
\hline 23 & SB & 23 & 941200 & 10,894 & 16,340 \\
\hline 24 & 23 & 24 & 940200 & 10,882 & 16,323 \\
\hline 25 & 24 & 25 & 933300 & 10,802 & 16,203 \\
\hline 26 & 25 & 26 & 927300 & 10,733 & 16,099 \\
\hline 27 & 26 & 27 & 63000 & 0,729 & 1,094 \\
\hline 28 & 26 & 28 & 857550 & 9,925 & 14,888 \\
\hline 29 & 28 & 29 & 835050 & 9,665 & 14,497 \\
\hline 30 & 29 & 30 & 52500 & 0,608 & 0,911 \\
\hline 31 & 30 & 31 & 767550 & 8,884 & 13,326 \\
\hline 32 & 31 & 32 & 137250 & 1,589 & 2,383 \\
\hline 33 & 32 & 33 & 124500 & 1,441 & 2,161 \\
\hline 34 & 31 & 34 & 599050 & 6,933 & 10,400 \\
\hline 35 & 34 & 35 & 107250 & 1,241 & 1,862 \\
\hline 36 & 34 & 36 & 448800 & 5,194 & 7,792 \\
\hline 37 & 36 & 37 & 48000 & 0,556 & 0,833 \\
\hline 38 & 36 & 38 & 393300 & 4,552 & 6,828 \\
\hline 39 & 38 & 39 & 99000 & 1,146 & 1,719 \\
\hline 40 & 38 & 40 & 270300 & 3,128 & 4,693 \\
\hline 41 & 40 & 41 & 175450 & 2,031 & 3,046 \\
\hline 42 & 40 & 42 & 94850 & 1,098 & 1,647 \\
\hline
\end{tabular}

Sumber : Analisa dan Perhitungan 
Tabel 3. Kebutuhan air bersih masing-masing titik simpul pada jaringan pipa 3

\begin{tabular}{|c|c|c|c|c|c|}
\hline \multirow{3}{*}{ No Pipa } & \multirow{2}{*}{\multicolumn{2}{|c|}{ Node }} & \multirow{2}{*}{\multicolumn{2}{|c|}{$\frac{\text { Debit (Q) }}{\text { Total }}$}} & \multirow{3}{*}{$\begin{array}{c}\text { Debit (Q) } \\
\text { Jam Puncak } \\
\text { (lt/dt) }\end{array}$} \\
\hline & & & & & \\
\hline & Dari & $\mathrm{Ke}$ & (lt/hr) & (lt/dt) & \\
\hline 43 & SB & 43 & 243900 & 2,823 & 4,234 \\
\hline 44 & 43 & 44 & 242900 & 2,811 & 4,217 \\
\hline 45 & 44 & 45 & 243900 & 2,823 & 4,234 \\
\hline 46 & 45 & 46 & 16000 & 0,185 & 0,278 \\
\hline 47 & 45 & 47 & 227900 & 2,638 & 3,957 \\
\hline 48 & 47 & 48 & 227900 & 2,638 & 3,957 \\
\hline 49 & 48 & 49 & 212150 & 2,455 & 3,683 \\
\hline 50 & 49 & 50 & 208400 & 2,412 & 3,618 \\
\hline 51 & 50 & 51 & 64150 & 0,742 & 1,114 \\
\hline 52 & 50 & 52 & 129000 & 1,493 & 2,240 \\
\hline
\end{tabular}

\section{Persiapan input data}

- Pemilihan kandidat pipa

Kandidat pipa yang digunakan diantaranya kandidat pipa ukuran diameter 3", 4", $5 ", 6 " \& 8$ " inch. Pemilihan ini berdasarkan pendekatan besaran debit dan kecepatan yang telah dihitung sebelumnya.

- Analisa harga satuan

Analisa harga satuan digunakan untuk mencari harga pekerjaan pemasangan pipa (harga upah + harga bahan). Dalam metode linear programming harga satuan pekerjaan digunakan sebagai parameter untuk meminimasi biaya akibat pemakaian diameter pipa. Berdasarkan analisa harga satuan pemerintah kota malang yahun 2016, didapat harga satuan untuk pemsangan Pipa PVC 8" = Rp. 360.632,/m1; Pipa PVC 6" = Rp. 240.463,-/m1; Pipa PVC 5" = Rp. 180.128,-/m1; Pipa
PVC 4" = Rp. 140.048,-/m1; dan Pipa PVC 3" = Rp. 94.226,-/m1.

- Perhitungan Kehilangan energi setiap kandidat pipa

Pokok permsalahan jaringan pipa dalam sistem penyediaan air bersih adalah kehilangan energi akibat gesekan. Besaran energi relatif pada setiap simpul layanan tergantung pada besaran kehilangan energi. Sedangakan, besaran kehilangan energi akibat gesekan tergantung dari besaran diameter pipa. Berdasarkan debit air pada setiap elemen pipa dan beberapa kandidat diameter pipa yang akan dipakai, maka dapat dihitung kehilangan energi pada setiap elemen pipa yang diakibatkan oleh besaran diameter pipa. Yang selanjutnya nilai-nilai kehilangan energi ini digunakan untuk menyusun salah satu fungsi pembatas yaitu batasan energi relatif.

Tabel 4. Kehilangan energi jaringan pipa 1

\begin{tabular}{|c|c|c|c|c|c|}
\hline \multirow{3}{*}{ No Pipa } & \multicolumn{5}{|c|}{ Kehilangan energi (m) } \\
\hline & $\begin{array}{c}\text { Kandidat pipa } \\
1\end{array}$ & $\begin{array}{c}\text { Kandidat } \\
\text { pipa } 2\end{array}$ & $\begin{array}{c}\text { Kandidat pipa } \\
3\end{array}$ & $\begin{array}{c}\text { Kandidat pipa } \\
4\end{array}$ & $\underset{5}{\text { Kandidat pipa }}$ \\
\hline & $\phi 8 ”$ & $\phi 6$ & $\phi 5 "$ & $\phi 4 "$ & $\phi 3 ”$ \\
\hline 1 & 0,285 & 1,156 & 2,806 & 8,310 & 33,690 \\
\hline 2 & 0,610 & 2,473 & 6,005 & 17,785 & 72,103 \\
\hline 3 & 0,566 & 2,294 & 5,570 & 16,496 & 66,874 \\
\hline 4 & 0,089 & 0,359 & 0,872 & 2,582 & 10,466 \\
\hline 5 & 2,059 & 8,348 & 20,268 & 60,025 & 243,343 \\
\hline 6 & 0,924 & 3,747 & 9,099 & 26,947 & 109,243 \\
\hline 7 & 0,581 & 2,356 & 5,720 & 16,939 & 68,671 \\
\hline 8 & 0,006 & 0,024 & 0,058 & 0,171 & 0,692 \\
\hline 9 & 0,276 & 1,120 & 2,719 & 8,053 & 32,646 \\
\hline 10 & 0,285 & 1,156 & 2,806 & 8,309 & 33,685 \\
\hline
\end{tabular}

Sumber : Hasil Perhitungan 
Lanjutan Tabel 4. Kehilangan energi jaringan pipa 1

\begin{tabular}{|c|c|c|c|c|c|}
\hline \multirow{3}{*}{ No Pipa } & \multicolumn{5}{|c|}{ Kehilangan energi (m) } \\
\hline & $\underset{1}{\text { Kandidat pipa }}$ & $\begin{array}{l}\text { Kandidat } \\
\text { pipa } 2\end{array}$ & $\begin{array}{l}\text { Kandidat pipa } \\
3\end{array}$ & $\begin{array}{l}\text { Kandidat pipa } \\
4\end{array}$ & $\begin{array}{l}\text { Kandidat pipa } \\
5\end{array}$ \\
\hline & $\phi 8 ”$ & $\phi 6 "$ & $\phi 5 "$ & $\phi 4 "$ & $\phi 3 "$ \\
\hline 11 & 0,008 & 0,031 & 0,076 & 0,226 & 0,917 \\
\hline 12 & 0,002 & 0,009 & 0,022 & 0,066 & 0,267 \\
\hline 13 & 0,001 & 0,006 & 0,014 & 0,041 & 0,168 \\
\hline 14 & 0,002 & 0,006 & 0,015 & 0,045 & 0,183 \\
\hline 15 & 0,001 & 0,002 & 0,006 & 0,018 & 0,072 \\
\hline 16 & 0,003 & 0,012 & 0,029 & 0,085 & 0,346 \\
\hline 17 & 0,007 & 0,029 & 0,070 & 0,209 & 0,845 \\
\hline 18 & 0,018 & 0,074 & 0,180 & 0,534 & 2,167 \\
\hline 19 & 0,002 & 0,007 & 0,018 & 0,052 & 0,211 \\
\hline 20 & 0,004 & 0,017 & 0,040 & 0,120 & 0,485 \\
\hline 21 & 0,001 & 0,004 & 0,009 & 0,028 & 0,113 \\
\hline 22 & 0,0001 & 0,001 & 0,001 & 0,004 & 0,016 \\
\hline
\end{tabular}

Sumber : Hasil Perhitungan

Tabel 5. Kehilangan energi jaringan pipa 2

\begin{tabular}{|c|c|c|c|c|c|}
\hline \multirow{3}{*}{ No Pipa } & \multicolumn{5}{|c|}{ Kehilangan energi (m) } \\
\hline & $\begin{array}{c}\text { Kandidat pipa } \\
1\end{array}$ & $\begin{array}{l}\text { Kandidat } \\
\text { pipa } 2\end{array}$ & $\begin{array}{l}\text { Kandidat pipa } \\
3\end{array}$ & $\underset{4}{\text { Kandidat pipa }}$ & $\underset{5}{\text { Kandidat pipa }}$ \\
\hline & $\phi 8 "$ & $\phi 6 "$ & $\phi 5 "$ & $\phi 4 "$ & $\phi 3 "$ \\
\hline 23 & 0,631 & 2,560 & 6,215 & 18,407 & 74,623 \\
\hline 24 & 0,866 & 3,512 & 8,527 & 25,254 & 102,382 \\
\hline 25 & 0,104 & 0,421 & 1,022 & 3,028 & 12,274 \\
\hline 26 & 0,586 & 2,377 & 5,772 & 17,095 & 69,305 \\
\hline 27 & 0,000 & 0,001 & 0,002 & 0,007 & 0,030 \\
\hline 28 & 1,307 & 5,297 & 12,862 & 38,091 & 154,423 \\
\hline 29 & 0,513 & 2,081 & 5,052 & 14,963 & 60,660 \\
\hline 30 & 0,000 & 0,000 & 0,001 & 0,003 & 0,010 \\
\hline 31 & 0,587 & 2,379 & 5,777 & 17,110 & 69,365 \\
\hline 32 & 0,013 & 0,052 & 0,125 & 0,372 & 1,506 \\
\hline 33 & 0,007 & 0,029 & 0,071 & 0,210 & 0,853 \\
\hline 34 & 0,304 & 1,232 & 2,990 & 8,856 & 35,901 \\
\hline 35 & 0,015 & 0,060 & 0,145 & 0,431 & 1,746 \\
\hline 36 & 0,010 & 0,039 & 0,094 & 0,279 & 1,131 \\
\hline 37 & 0,000 & 0,002 & 0,005 & 0,014 & 0,056 \\
\hline 38 & 0,025 & 0,103 & 0,251 & 0,743 & 3,013 \\
\hline 39 & 0,005 & 0,020 & 0,050 & 0,147 & 0,597 \\
\hline 40 & 0,001 & 0,006 & 0,015 & 0,044 & 0,177 \\
\hline 41 & 0,036 & 0,145 & 0,351 & 1,041 & 4,220 \\
\hline 42 & 0,018 & 0,074 & 0,179 & 0,529 & 2,146 \\
\hline
\end{tabular}

Sumber : Hasil Perhitungan

Tabel 6 Kehilangan energi jaringan pipa 3

\begin{tabular}{|c|c|c|c|c|c|}
\hline \multirow{3}{*}{ No Pipa } & \multicolumn{5}{|c|}{ Kehilangan energi (m) } \\
\hline & $\begin{array}{c}\text { Kandidat pipa } \\
1\end{array}$ & $\begin{array}{l}\text { Kandidat } \\
\text { pipa } 2\end{array}$ & $\begin{array}{c}\text { Kandidat pipa } \\
3\end{array}$ & $\begin{array}{c}\text { Kandidat pipa } \\
4\end{array}$ & $\begin{array}{c}\text { Kandidat pipa } \\
5\end{array}$ \\
\hline & $\phi 8^{\prime \prime}$ & $\phi 6 "$ & $\phi 5 "$ & $\phi 4 "$ & $\phi 3^{\prime \prime}$ \\
\hline 43 & 0,044 & 0,180 & 0,438 & 1,297 & 5,258 \\
\hline 44 & 0,012 & 0,050 & 0,121 & 0,359 & 1,453 \\
\hline 45 & 0,006 & 0,025 & 0,061 & 0,181 & 0,732 \\
\hline 46 & 0,000 & 0,001 & 0,002 & 0,005 & 0,019 \\
\hline 47 & 0,008 & 0,034 & 0,082 & 0,242 & 0,982 \\
\hline 48 & 0,014 & 0,056 & 0,136 & 0,401 & 1,628 \\
\hline 49 & 0,047 & 0,191 & 0,465 & 1,376 & 5,578 \\
\hline
\end{tabular}

Sumber : Hasil Perhitungan 
Lanjutan Tabel 6. Kehilangan energi jaringan pipa 3

\begin{tabular}{|c|c|c|c|c|c|}
\hline \multirow{3}{*}{ No Pipa } & \multicolumn{5}{|c|}{ Kehilangan energi (m) } \\
\hline & $\begin{array}{c}\text { Kandidat pipa } \\
1\end{array}$ & $\begin{array}{c}\text { Kandidat } \\
\text { pipa } 2\end{array}$ & $\begin{array}{l}\text { Kandidat pipa } \\
3\end{array}$ & $\begin{array}{l}\text { Kandidat pipa } \\
4\end{array}$ & $\begin{array}{c}\text { Kandidat pipa } \\
5\end{array}$ \\
\hline & $\phi 8 "$ & $\phi 6 "$ & $\phi 5$ & $\phi 4 ”$ & $\phi 3 ”$ \\
\hline 50 & 0,046 & 0,185 & 0,450 & 1,331 & 5,397 \\
\hline 51 & 0,002 & 0,010 & 0,024 & 0,071 & 0,286 \\
\hline 52 & 0,019 & 0,076 & 0,185 & 0,549 & 2,227 \\
\hline
\end{tabular}

Tabel 7. Kehilangan energi per satuan panjang jaringan pipa 1

\begin{tabular}{|c|c|c|c|c|c|}
\hline \multirow{3}{*}{ No Pipa } & \multicolumn{5}{|c|}{$\mathrm{J}(\mathrm{m})$} \\
\hline & Kandidat pipa 1 & $\begin{array}{l}\text { Kandidat } \\
\text { pipa } 2\end{array}$ & $\begin{array}{l}\text { Kandidat pipa } \\
3\end{array}$ & $\begin{array}{l}\text { Kandidat pipa } \\
4\end{array}$ & $\begin{array}{l}\text { Kandidat pipa } \\
5\end{array}$ \\
\hline & $\phi 8 "$ & $\phi 6 "$ & $\phi 5 "$ & $\phi 4 "$ & $\phi 3 "$ \\
\hline 1 & 0,0012 & 0,0048 & 0,0117 & 0,0348 & 0,1410 \\
\hline 2 & 0,0012 & 0,0048 & 0,0116 & 0,0343 & 0,1389 \\
\hline 3 & 0,0012 & 0,0048 & 0,0117 & 0,0347 & 0,1405 \\
\hline 4 & 0,0012 & 0,0048 & 0,0116 & 0,0344 & 0,1396 \\
\hline 5 & 0,0011 & 0,0046 & 0,0111 & 0,0328 & 0,1330 \\
\hline 6 & 0,0011 & 0,0045 & 0,0109 & 0,0323 & 0,1311 \\
\hline 7 & 0,0011 & 0,0044 & 0,0108 & 0,0319 & 0,1293 \\
\hline 8 & 0,0000 & 0,0001 & 0,0002 & 0,0005 & 0,0019 \\
\hline 9 & 0,0008 & 0,0034 & 0,0082 & 0,0244 & 0,0989 \\
\hline 10 & 0,0006 & 0,0025 & 0,0061 & 0,0180 & 0,0729 \\
\hline 11 & 0,00002 & 0,0001 & 0,0002 & 0,0006 & 0,0025 \\
\hline 12 & 0,0003 & 0,0013 & 0,0032 & 0,0094 & 0,0382 \\
\hline 13 & 0,0001 & 0,0005 & 0,0012 & 0,0034 & 0,0140 \\
\hline 14 & 0,00001 & 0,00004 & 0,0001 & 0,0003 & 0,0012 \\
\hline 15 & 0,0001 & 0,0003 & 0,0007 & 0,0020 & 0,0079 \\
\hline 16 & 0,00002 & 0,0001 & 0,0002 & 0,0006 & 0,0023 \\
\hline 17 & 0,00002 & 0,0001 & 0,0002 & 0,0005 & 0,0021 \\
\hline 18 & 0,0001 & 0,0002 & 0,0005 & 0,0016 & 0,0064 \\
\hline 19 & 0,000005 & 0,0000 & 0,0001 & 0,0002 & 0,0006 \\
\hline 20 & 0,000016 & 0,0001 & 0,0002 & 0,0005 & 0,0019 \\
\hline 21 & 0,000006 & 0,000023 & 0,0001 & 0,0002 & 0,0007 \\
\hline 22 & 0,000001 & 0,000003 & 0,00001 & 0,00002 & 0,0001 \\
\hline
\end{tabular}

Sumber : Hasil Perhitungan

Tabel 8. Kehilangan energi per satuan panjang jaringan pipa 2

\begin{tabular}{|c|c|c|c|c|c|}
\hline \multirow{3}{*}{ No Pipa } & \multicolumn{5}{|c|}{$\mathrm{J}(\mathrm{m})$} \\
\hline & $\begin{array}{c}\text { Kandidat pipa } \\
1\end{array}$ & $\begin{array}{l}\text { Kandidat } \\
\text { pipa } 2\end{array}$ & $\begin{array}{c}\text { Kandidat pipa } \\
3\end{array}$ & $\begin{array}{c}\text { Kandidat pipa } \\
4\end{array}$ & $\underset{5}{\text { Kandidat pipa }}$ \\
\hline & $\phi 8 "$ & $\phi 6 "$ & $\phi 5 "$ & $\phi 4 "$ & $\phi 3 "$ \\
\hline 23 & 0,0015 & 0,0061 & 0,0148 & 0,0439 & 0,1781 \\
\hline 24 & 0,0015 & 0,0061 & 0,0148 & 0,0438 & 0,1777 \\
\hline 25 & 0,0015 & 0,0060 & 0,0146 & 0,0433 & 0,1753 \\
\hline 26 & 0,0015 & 0,0059 & 0,0144 & 0,0427 & 0,1733 \\
\hline 27 & 0,00001 & 0,00004 & 0,0001 & 0,0003 & 0,0012 \\
\hline 28 & 0,0013 & 0,0051 & 0,0125 & 0,0370 & 0,1499 \\
\hline 29 & 0,0012 & 0,0049 & 0,0119 & 0,0352 & 0,1427 \\
\hline 30 & 0,00001 & 0,00003 & 0,0001 & 0,0002 & 0,0009 \\
\hline 31 & 0,0010 & 0,0042 & 0,0102 & 0,0301 & 0,1221 \\
\hline 32 & 0,00004 & 0,0002 & 0,0004 & 0,0012 & 0,0051 \\
\hline 33 & 0,00004 & 0,0001 & 0,0004 & 0,0010 & 0,0042 \\
\hline 34 & 0,0007 & 0,0026 & 0,0064 & 0,0190 & 0,0772 \\
\hline 35 & 0,00003 & 0,0001 & 0,0003 & 0,0008 & 0,0032 \\
\hline
\end{tabular}

Sumber : Hasil Perhitungan 
Lanjutan Tabel 8. Kehilangan energi per satuan panjang jaringan pipa 2

\begin{tabular}{|c|c|c|c|c|c|}
\hline \multirow{3}{*}{ No Pipa } & \multicolumn{5}{|c|}{$\mathrm{J}(\mathrm{m})$} \\
\hline & $\begin{array}{c}\text { Kandidat pipa } \\
1\end{array}$ & $\begin{array}{l}\text { Kandidat } \\
\text { pipa } 2\end{array}$ & $\begin{array}{l}\text { Kandidat pipa } \\
3\end{array}$ & $\begin{array}{l}\text { Kandidat pipa } \\
4\end{array}$ & $\begin{array}{l}\text { Kandidat pipa } \\
5\end{array}$ \\
\hline & $\phi 8^{\prime \prime}$ & $\phi 6 "$ & $\phi 5 "$ & $\phi 4 "$ & $\phi 3 "$ \\
\hline 36 & 0,0004 & 0,0016 & 0,0038 & 0,0112 & 0,0453 \\
\hline 37 & 0,00001 & 0,00002 & 0,0001 & 0,0002 & 0,0007 \\
\hline 38 & 0,0003 & 0,0012 & 0,0030 & 0,0087 & 0,0354 \\
\hline 39 & 0,00002 & 0,0001 & 0,0002 & 0,0007 & 0,0028 \\
\hline 40 & 0,0001 & 0,0006 & 0,0015 & 0,0044 & 0,0177 \\
\hline 41 & 0,0001 & 0,0003 & 0,0007 & 0,0020 & 0,0080 \\
\hline 42 & 0,00002 & 0,0001 & 0,0002 & 0,0006 & 0,0026 \\
\hline
\end{tabular}

Sumber : Hasil Perhitungan

Tabel 9. Kehilangan energi per satuan panjang jaringan pipa 3

\begin{tabular}{|c|c|c|c|c|c|}
\hline \multirow{3}{*}{ No Pipa } & \multicolumn{5}{|c|}{$\mathrm{J}(\mathrm{m})$} \\
\hline & $\begin{array}{c}\text { Kandidat pipa } \\
1\end{array}$ & $\begin{array}{l}\text { Kandidat } \\
\text { pipa } 2\end{array}$ & $\begin{array}{c}\text { Kandidat pipa } \\
3\end{array}$ & $\begin{array}{l}\text { Kandidat pipa } \\
4\end{array}$ & $\begin{array}{l}\text { Kandidat pipa } \\
5\end{array}$ \\
\hline & $\phi 8 "$ & $\phi 6 "$ & $\phi 5 "$ & $\phi 4 "$ & $\phi 3 "$ \\
\hline 43 & 0,0001 & 0,0005 & 0,0012 & 0,0036 & 0,0146 \\
\hline 44 & 0,0001 & 0,0005 & 0,0012 & 0,0036 & 0,0145 \\
\hline 45 & 0,0001 & 0,0005 & 0,0012 & 0,0036 & 0,0146 \\
\hline 46 & 0,000001 & 0,000003 & 0,000008 & 0,000023 & 0,0001 \\
\hline 47 & 0,0001 & 0,0004 & 0,0011 & 0,0032 & 0,0129 \\
\hline 48 & 0,0001 & 0,0004 & 0,0011 & 0,0032 & 0,0129 \\
\hline 49 & 0,0001 & 0,0004 & 0,0009 & 0,0028 & 0,0113 \\
\hline 50 & 0,0001 & 0,0004 & 0,0009 & 0,0027 & 0,0109 \\
\hline 51 & 0,00001 & 0,00004 & 0,0001 & 0,0003 & 0,0012 \\
\hline 52 & 0,00004 & 0,0002 & 0,0004 & 0,0011 & 0,0045 \\
\hline
\end{tabular}

\section{Perumusan model linear programming}

Optimasi jaringan pipa dengan menggunakan Linear Programming terdiri dari fungsi tujuan dan fungsi pembatas.

\section{Fungsi tujuan}

Fungsi tujuan : berfungsi sebagai parameter meminimasi biaya

$\mathrm{Z} \min =\mathrm{C} 11 . \mathrm{X} 11+\mathrm{C} 12 . \mathrm{X} 12+\mathrm{C} 13 . \mathrm{X} 13+$

C14.X14 + C15.X15 + .Cnn.Xnn

Dimana :

C11: Cost kandidat pipa 1 elemen pipa 1

X11: Panjang pipa 1 kandidat pipa $1(\mathrm{~m})$

C12: Cost kandidat pipa 2 elemen pipa 1

$\mathrm{X} 12$ : Panjang pipa 1 kandidat pipa $2(\mathrm{~m})$

C13: Cost kandidat pipa 3 elemen pipa 1

X13: Panjang pipa 1 kandidat pipa $3(\mathrm{~m})$

C14: Cost kandidat pipa 4 elemen pipa 1

X14: Panjang pipa 1 kandidat pipa $4(\mathrm{~m})$

C15: Cost kandidat pipa 5 elemen pipa 1
X15: Panjang pipa 1 kandidat pipa $5(\mathrm{~m})$ Cnn: Cost kandidat pipa n elemen pipa $n$ Xnn: Panjang pipa $\mathrm{n}$ kandidat pipa $\mathrm{n}(\mathrm{m})$

\section{Fungsi pembatas}

Batas panjang pipa : berfungsi agar panjang pipa setiap elemen pipa nilainya tetap.

$\mathrm{X} 11+\mathrm{X} 12+\mathrm{X} 13+\mathrm{X} 14+\mathrm{X} 15=\mathrm{X} 1$

$\mathrm{X} 21+\mathrm{X} 22+\mathrm{X} 23+\mathrm{X} 24+\mathrm{X} 25=\mathrm{X} 2$

$\mathrm{X} 31+\mathrm{X} 32+\mathrm{X} 33+\mathrm{X} 34+\mathrm{X} 35=\mathrm{X} 3$

$\mathrm{X} 41+\mathrm{X} 42+\mathrm{X} 43+\mathrm{X} 44+\mathrm{X} 45=\mathrm{X} 4$

$X 51+X 52+X 53+X 54+X 55=X 5$

$X n n+X n n+X n n+X n n+X n n=n n$

Dimana :

X11: Panjang pipa 1 untuk kandidat pipa $1(\mathrm{~m})$ X12: Panjang pipa 1 untuk kandidat pipa $2(\mathrm{~m})$ X13:Panjang pipa 1 untuk kandidat pipa $3(\mathrm{~m})$ X14:Panjang pipa 1 untuk kandidat pipa $4(\mathrm{~m})$ X15:Panjang pipa 1 untuk kandidat pipa 5 (m) Xnn:Panjang pipa $\mathrm{n}$ untuk kandidat pipa $\mathrm{n}(\mathrm{m})$ 
Batasan energy relatif : berfungsi untuk membatasi besaran energi relatif setiap simpul agar memenuhi standart ijin energi relatif yang ditetapkan.

(EL sumber - EL simpul $\mathrm{n}-\mathrm{H}$ bawah) $\geq$ $\mathrm{J} 11 . \mathrm{X} 11+\mathrm{J} 12 . \mathrm{X} 12+\mathrm{J} 13 . \mathrm{X} 13+\mathrm{J} 14 \mathrm{X} 14+$ $\mathrm{J} 15 \mathrm{X} 15+\mathrm{J} 21 . \mathrm{X} 21+\mathrm{J} 22 . \mathrm{X} 22+\mathrm{J} 23 . \mathrm{X} 23+$ $\mathrm{J} 24 \mathrm{X} 24+\mathrm{J} 25 \mathrm{X} 25+\ldots \ldots \ldots \ldots \ldots . . . . . \mathrm{Jnn} . \mathrm{Xnn}$ $\geq($ EL sumber - EL simpul $\mathrm{n}-\mathrm{H}$ atas $)$

Dimana :

EL sumber : Elevasi muka air sumber air/tendon (m)

EL simpul : Elevasi simpul (m)

$\mathrm{H}$ bawah : Batas energi relatif minimum yang diijinkan pada setiap simpul layanan $(7 \mathrm{~m})$

$\mathrm{H}$ atas : Batas energi relatif maksimum yang diijinkan pada setiap simpul layanan $(20 \mathrm{~m})$

X11 : Panjang pipa 1 kandidat pipa 1

J11 : Kehilangan energy elemen pipa 1 untuk kandidat pipa 1

X12 : Panjang pipa 1 kandidat pipa 2

J12 : Kehilangan energy elemen pipa 1 untuk kandidat pipa 2

X13 : Panjang pipa 1 kandidat pipa 3

J13 : Kehilangan energy elemen pipa 1 untuk kandidat pipa 3

X14 : Panjang pipa 1 kandidat pipa 4

J14 : Kehilangan energy elemen pipa 1 untuk kandidat pipa 4

X15 : Panjang pipa 1 kandidat pipa 5

J15 : Kehilangan energy elemen pipa 1 untuk kandidat pipa 4

Jnn : Kehilangan energy elemen pipa $n$ untuk kandidat pipa $\mathrm{n}$

Xnn : Panjang pipa $\mathrm{n}$ kandidat pipa $\mathrm{n}$

Non Negativasi : berfungsi agar nilai variabel yang dicari tidak bernilai negatif.

$\mathrm{X} 11 \geq 0$

$\mathrm{X} 12 \geq 0$

$\mathrm{X} 13 \geq 0$

$\mathrm{X} 14 \geq 0$

$\mathrm{X} 15 \geq 0$

$\mathrm{Xnn} \geq 0$

\section{Running Program}

Aplikasi yang digunakan untuk running program adalah Aplikasi LINDO. Untuk menentukan nilai optimal dengan menggunakan Lindo diperlukan beberapa tahapan yaitu:

- Menentukan model matematika berdasarkan data real

- Menentukan formulasi program untuk Lindo

- Membaca hasil report yang dihasilkan oleh Lindo.

\section{Penentuan Diameter Pipa}

Penentuan diameter pipa dilakukan karena hasil report dari proses running program berupa panjang pipa. Dimana panjang pipa ini bertindak sebagai perwakilan kandidat diameter pipa. Sehingga penentuan diameter pipa dilakukan secara manual.

Tabel 10. Penentuan Diameter Pipa "Jaringan

Pipa 1"

\begin{tabular}{|c|c|c|c|c|}
\hline $\begin{array}{c}\text { Elemen } \\
\text { pipa }\end{array}$ & $\begin{array}{c}\text { Kandidat } \\
\text { Pipa }\end{array}$ & Value & $\begin{array}{c}\varnothing \\
\text { (LP) } \\
\text { (inch) }\end{array}$ & $\begin{array}{c}\varnothing \\
\text { Existing } \\
\text { (inch) }\end{array}$ \\
\hline$\overline{1}$ & $\overline{1}$ & 239 & $8 "$ & $8^{\prime \prime}$ \\
\hline 2 & 1 & 519 & $8 "$ & $8 "$ \\
\hline 3 & 1 & 476 & 8" & $8 "$ \\
\hline 4 & 1 & 75 & $8 "$ & $8 "$ \\
\hline 5 & $\begin{array}{l}1 \\
2\end{array}$ & $\begin{array}{c}204 \\
1624\end{array}$ & $\begin{array}{l}8 " \\
6 "\end{array}$ & $8^{\prime \prime}$ \\
\hline 6 & 2 & 833 & $6 "$ & $8 "$ \\
\hline 7 & 2 & 531 & $6 "$ & $6 "$ \\
\hline 8 & 5 & 336 & 3" & 3" \\
\hline 9 & 3 & 330 & $5 "$ & $6 "$ \\
\hline 10 & 3 & 462 & $5 "$ & $6 "$ \\
\hline 11 & 5 & 367 & 3" & $4 "$ \\
\hline 12 & 3 & 7 & $5 "$ & 6" \\
\hline 13 & 5 & 12 & 3" & 4" \\
\hline 14 & 5 & 155 & 3" & $4 "$ \\
\hline 15 & 5 & 9 & 3" & $4 "$ \\
\hline 16 & 5 & 148 & 3" & $4 "$ \\
\hline 17 & 5 & 408 & 3" & $4 "$ \\
\hline 18 & 4 & 339 & 4" & $4 "$ \\
\hline 19 & 5 & 329 & 3" & 4" \\
\hline 20 & 5 & 254 & 3" & 4" \\
\hline 21 & 5 & 170 & 3" & $4 "$ \\
\hline 22 & 5 & 173 & 3" & 4" \\
\hline
\end{tabular}

Sumber : Hasil Running LP 
Tabel 11. Penentuan Diameter Pipa "Jaringan

Pipa 2"

\begin{tabular}{|c|c|c|c|c|}
\hline $\begin{array}{l}\text { Elemen } \\
\text { pipa }\end{array}$ & $\begin{array}{c}\text { Kandidat } \\
\text { Pipa }\end{array}$ & Value & $\begin{array}{c}\varnothing \\
\text { (LP) } \\
\text { (inch) }\end{array}$ & $\begin{array}{l}\varnothing \text { Existing } \\
\text { (inch) }\end{array}$ \\
\hline 23 & 1 & 419 & $8 "$ & $8 "$ \\
\hline 24 & 1 & 576 & $8 "$ & $8 "$ \\
\hline 25 & 1 & 70 & $8 "$ & $8 "$ \\
\hline 26 & 1 & 400 & $8 "$ & $8 "$ \\
\hline 27 & 5 & 25 & $3 "$ & $3 "$ \\
\hline 28 & 2 & 1030 & $6 "$ & $6 "$ \\
\hline 29 & 2 & 425 & $6 "$ & $6 "$ \\
\hline 30 & 5 & 12 & $3 "$ & $4 "$ \\
\hline 31 & 3 & 568 & $5 "$ & $5 "$ \\
\hline 32 & 5 & 298 & $3 "$ & $3 "$ \\
\hline 33 & 5 & 202 & $3 "$ & $3 "$ \\
\hline 34 & 3 & 465 & $5 "$ & $5 "$ \\
\hline 35 & 5 & 545 & $3 "$ & $4 "$ \\
\hline 36 & 4 & 25 & $4 "$ & $4 "$ \\
\hline 37 & 5 & 77 & $3 "$ & $3 "$ \\
\hline 38 & 5 & 85 & $3 "$ & $3 "$ \\
\hline 39 & 5 & 219 & $3 "$ & $3 "$ \\
\hline 40 & 5 & 10 & $3 "$ & $3 "$ \\
\hline 41 & 5 & 530 & $3 "$ & $4 "$ \\
\hline 42 & 5 & 841 & $3 "$ & $4 "$ \\
\hline
\end{tabular}

Sumber : Hasil Running LP
Tabel 12. Penentuan Diameter Pipa "Jaringan

Pipa 3"

\begin{tabular}{ccccc}
\hline $\begin{array}{c}\text { Elemen } \\
\text { pipa }\end{array}$ & $\begin{array}{c}\text { Kandidat } \\
\text { Pipa }\end{array}$ & Value & $\begin{array}{c}\varnothing(\mathrm{LP}) \\
\text { (inch) }\end{array}$ & $\begin{array}{c}\varnothing \text { Existing } \\
\text { (inch) }\end{array}$ \\
\hline 43 & 4 & 359 & $4 "$ & $6 "$ \\
44 & 4 & 100 & $4 "$ & $6 "$ \\
45 & 4 & 50 & $4 "$ & $6 "$ \\
46 & 5 & 200 & $3 "$ & $3 "$ \\
47 & 4 & 76 & $4 "$ & $6 "$ \\
48 & 4 & 226 & $4 "$ & $5 "$ \\
49 & 4 & 493 & $4 "$ & $5 "$ \\
50 & 5 & 493 & $3 "$ & $5 "$ \\
51 & 5 & 231 & $3 "$ & $3 "$ \\
52 & 5 & 494 & $3 "$ & $3 "$ \\
\hline
\end{tabular}

Sumber : Hasil Running LP

\section{Kontrol Energi Relatif}

Kontrol energi dilakukan untuk melihat apakah hasil pencarian diameter pipa optimal menggunakan metode program linear ini benarbenar tercapai. Kontrol energi ini dilakukan dengan cara menghitung secara manual dengan bantuan aplikasi Microsoft Exel. Sesuai dari hasil analisa yang telah dilakukan, terbukti bahwa batas energi relatif ijin setiap simpul layanan benar-benar tercapai yaitu antara +7 meter sampai +20 meter.

Tabel 13. Energi absolut dan relatif untuk Jaringan Pipa 1

\begin{tabular}{|c|c|c|c|c|c|c|}
\hline \multirow[t]{2}{*}{ No } & \multirow[t]{2}{*}{ Simpul } & \multirow[t]{2}{*}{ Elevasi } & $\begin{array}{c}\text { Debit } \\
\text { Kebutuhan }\end{array}$ & $\begin{array}{c}\text { Energi Absolut } \\
\text { LP }\end{array}$ & $\begin{array}{c}\text { Energi Relatif } \\
\text { LP }\end{array}$ & $\begin{array}{l}\text { Energi Relatif } \\
\text { Esisting }\end{array}$ \\
\hline & & & (m3/dt) & (m) & (m) & (m) \\
\hline 1 & Simpul 8 & 427 & 0.00141 & 434.009 & 7.009 & 15.471 \\
\hline 2 & Simpul 11 & 416 & 0.00163 & 428.909 & 12.909 & 24.610 \\
\hline 3 & Simpul 14 & 415 & 0.00109 & 429.007 & 13.803 & 25.740 \\
\hline 4 & Simpul 16 & 412 & 0.00157 & 428.772 & 16.568 & 28.682 \\
\hline 5 & Simpul 17 & 418 & 0.00147 & 428.273 & 10.069 & 22.559 \\
\hline 6 & Simpul 19 & 421 & 0.00078 & 428.372 & 7.169 & 19.181 \\
\hline 7 & Simpul 21 & 419 & 0.00079 & 427.986 & 8.783 & 21.086 \\
\hline 8 & Simpul 22 & 420 & 0.00027 & 428.083 & 7.879 & 20.110 \\
\hline
\end{tabular}

Sumber : hasil Perhitungan

Tabel 14. Energi absolut dan relatif untuk Jaringan Pipa 2

\begin{tabular}{rcccccc}
\hline \multirow{2}{*}{ No } & Simpul & Elevasi & $\begin{array}{c}\text { Debit } \\
\text { Kebutuhan }\end{array}$ & $\begin{array}{c}\text { Energi Absolut } \\
\text { LP }\end{array}$ & $\begin{array}{c}\text { Energi Relatif } \\
\text { LP }\end{array}$ & $\begin{array}{c}\text { Energi Relatif } \\
\text { Exisitng }\end{array}$ \\
\cline { 3 - 7 } & & $(\mathrm{m} 3 / \mathrm{dt})$ & $(\mathrm{m})$ & $(\mathrm{m})$ & $(\mathrm{m})$ \\
\hline 1 & Simpul 27 & 440 & 0.00109 & 447.782 & 7.782 & 7.782 \\
2 & Simpul 30 & 425 & 0.00091 & 440.424 & 15.424 & 15.431 \\
3 & Simpul 33 & 421 & 0.00216 & 432.297 & 11.297 & 11.297 \\
\hline
\end{tabular}

Sumber : hasil Perhitungan 
Lanjutan Tabel 14. Energi absolut dan relatif untuk Jaringan Pipa 2

\begin{tabular}{rcccccc}
\hline \multirow{2}{*}{ No } & Simpul & Elevasi & $\begin{array}{c}\text { Debit } \\
\text { Kebutuhan }\end{array}$ & $\begin{array}{c}\text { Energi Absolut } \\
\text { LP }\end{array}$ & $\begin{array}{c}\text { Energi Relatif } \\
\text { LP }\end{array}$ & $\begin{array}{c}\text { Energi Relatif } \\
\text { Exisitng }\end{array}$ \\
\cline { 4 - 7 } & & & $(\mathrm{m} 3 / \mathrm{dt})$ & $(\mathrm{m})$ & $(\mathrm{m})$ & $(\mathrm{m})$ \\
\hline 4 & Simpul 35 & 417 & 0.00186 & 429.921 & 12.921 & 14.236 \\
5 & Simpul 37 & 420 & 0.00083 & 431.331 & 11.331 & 11.331 \\
6 & Simpul 39 & 419 & 0.00172 & 427.778 & 8.778 & 8.769 \\
7 & Simpul 41 & 416 & 0.00305 & 423.977 & 7.977 & 11.156 \\
8 & Simpul 42 & 419 & 0.00165 & 426.051 & 7.051 & 8.668 \\
\hline
\end{tabular}

Sumber : hasil Perhitungan

Tabel 15. Energi absolut dan relatif untuk Jaringan Pipa 3

\begin{tabular}{rcccccc}
\hline \multirow{2}{*}{ No } & \multirow{2}{*}{ Simpul } & Elevasi & $\begin{array}{c}\text { Debit } \\
\text { Kebutuhan }\end{array}$ & $\begin{array}{c}\text { Energi Absolut } \\
\text { LP }\end{array}$ & $\begin{array}{c}\text { Energi Relatif } \\
\text { LP }\end{array}$ & $\begin{array}{c}\text { Energi Relatif } \\
\text { Existing }\end{array}$ \\
\cline { 4 - 7 } & & & $(\mathrm{m} 3 / \mathrm{dt})$ & $(\mathrm{m})$ & $(\mathrm{m})$ & $(\mathrm{m})$ \\
\hline 1 & Simpul 46 & 439 & 0.00028 & 448.145 & 9.145 & 10.726 \\
2 & Simpul 51 & 425 & 0.00111 & 440.462 & 15.462 & 23.268 \\
3 & Simpul 52 & 429 & 0.00224 & 438.521 & 9.521 & 17.327 \\
\hline
\end{tabular}

Sumber : hasil Perhitungan

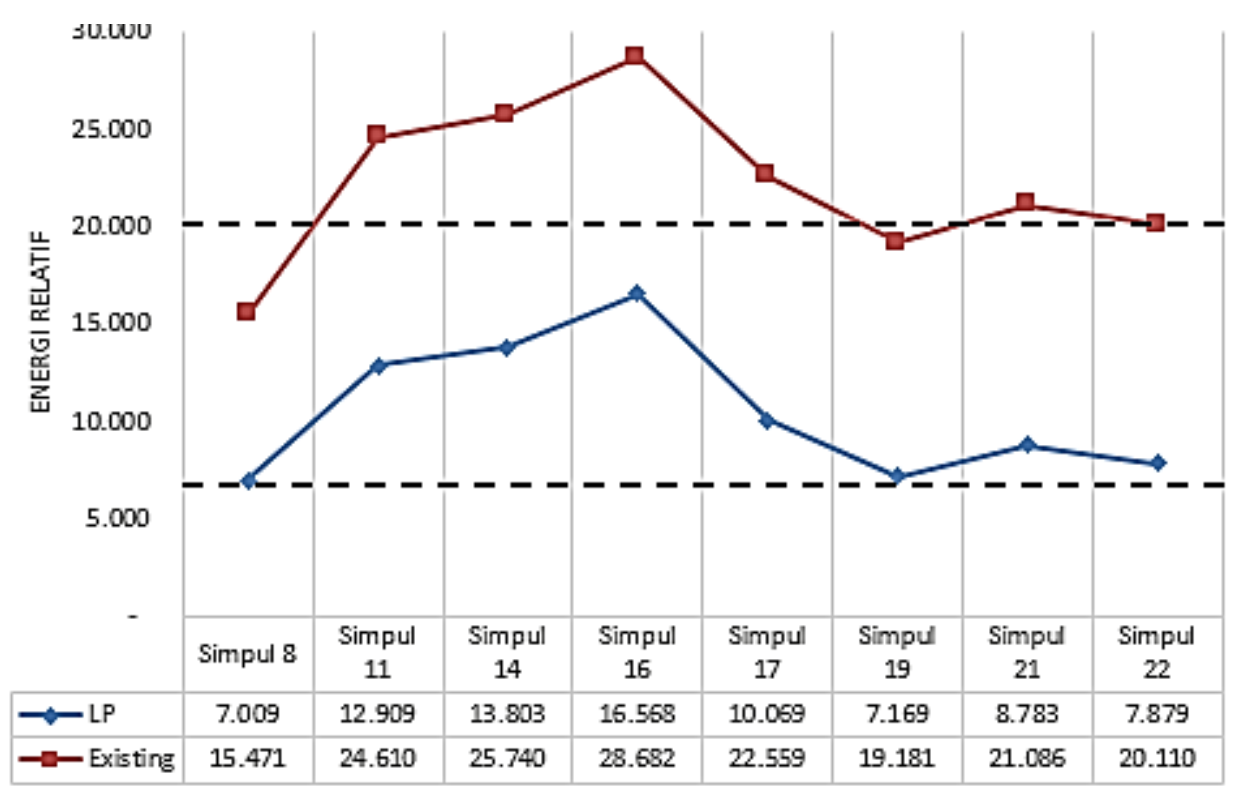

Gambar 5. Grafik Energi Relatif Jaringan Pipa 1 


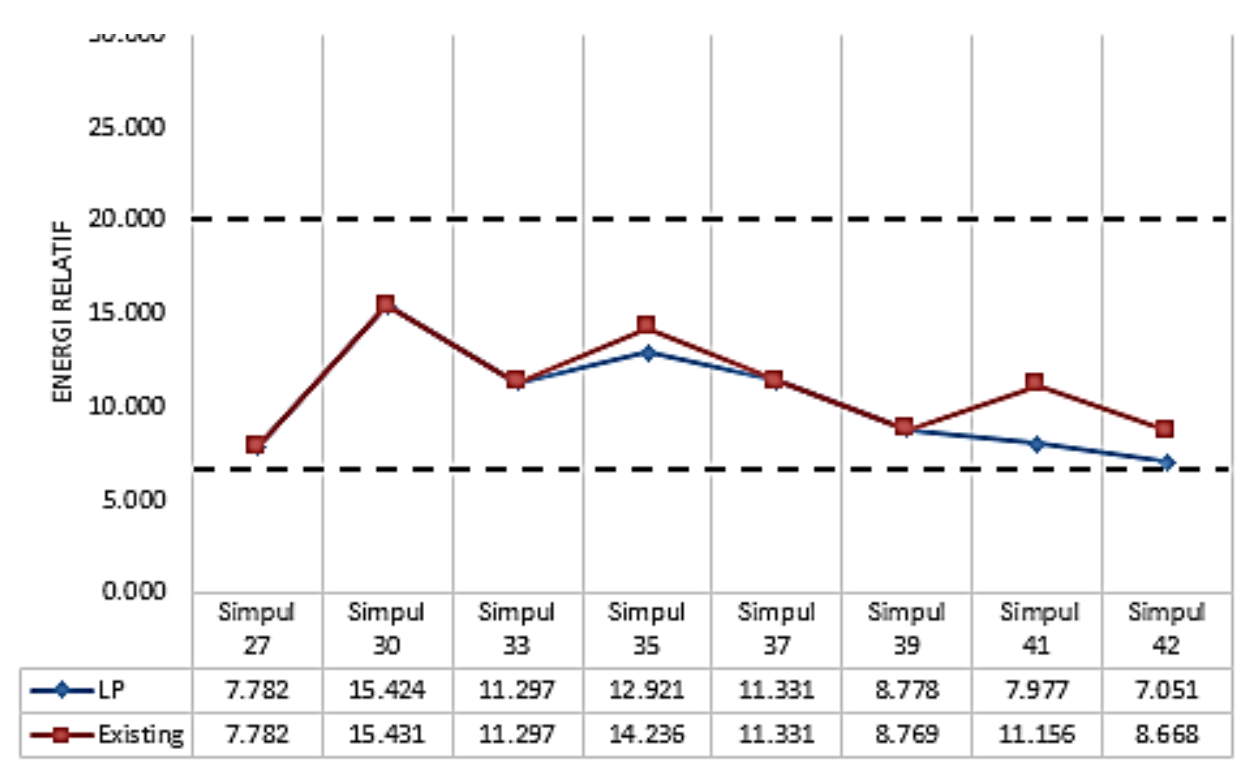

Gambar 6. Grafik Energi Relatif Jaringan Pipa 2

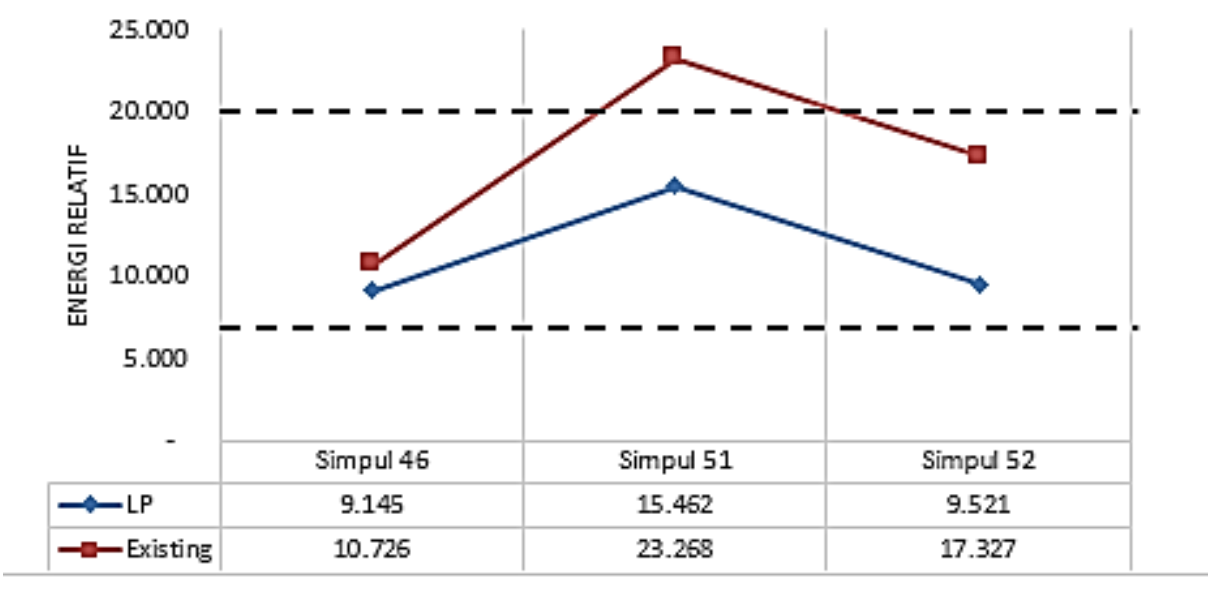

Gambar 7. Grafik Energi Relatif Jaringan Pipa 3

\section{KESIMPULAN DAN SARAN}

\section{Kesimpulan}

Sistem

persamaan

Linear

Programming yang dikembangkan mampu menyelesaikan masalah pencarian diameter optimum pada system jaringan pipa terbuka.

Terbukti bahwa batas energi relatif ijin setiap simpul layanan benar-benar tercapai yaitu antara +7 meter sampai +20 meter. Sehingga minimasi biaya akibat pemakaian diameter pipa dapat teratasi.

\section{Saran}

Sistem persamaan hidrolis jaringan pipa yang dikembangkan dalam karya ini terbatas pada sistem jaringan pipa terbuka karena permasalahannya yang simplek. Untuk sistem jaringan pipa yang bersifat tertutup (loop) harus menggunakan metode lain yang lebih handal dalam menyelesaikan optimasi diameter, hal ini dikarenakan permasalah pada sistem jaringan pipa tertutup bersifat non linier atau komplek. Pengembangan model dengan basis analisis ini dapat menjadi peluang untuk kegiatan penelitian berikutnya.

Lindo merupakan program khusus yang didisain untuk menyelesaikan permasalahan optimasi. Adanya keterbatasan jumlah variabel menyebabkan program ini tidak berfungsi. Penggunaan program lain dapat dipertimbangkan untuk menyelesaikan masalah optimasi yang menggunakan metode linear programming. 


\section{DAFTAR PUSTAKA}

Klass, Dua K. Y. S, 2009, Desain Jaringan Pipa Prinsip Dasar Aplikasi, CV. Mandar Maju, Bandung.

Noerbambang, M. Soufyan, Takeo Morimura. 2000. Perecanaan dan Pemeliharaan Sistem Plambing, PT. Pradnya Paramitha, Jakarta.

Mangkoedihardjo, Sarwoko. 1985, Penyediaan Air Bersih I : Dasar-dasar Perencanaan dan Evaluasi Kebutuhan Air. FTSP-ITS, Surabaya.

Permana, Rega Putra., 2013.Optimasi Diameter Pipa Pada Sistem Jaringan Air Bersih Dengan Menggunakan Linear Programming Di Kecamatan Turen Malang. Skripsi Jurusan Teknik Sipil Universitas Muhammadiyah Malang.

Triadmodjo, Bambang, 1996, Hidrolika II. Beta off set, Yogyakarta.

Sulianto, 2013, "Linear Programming untuk Pencarian Diameter Optimum Pada Jaringan Pipa Terbuka Dalam Sistem Penyediaan Air Bersih", Jurnal Penelitian Program PBP, UMM, Malang, Indonesia.

Giles V., Ronald, Joseph, Soemitro, 1986, Mekanika Fluida dan Hidrologi, Angkasa, Erlangga, Jakarta.

Ray K., Linsley, Joseph B Franzini, 1996, Teknik Sumber Daya Air. Jilid I dan Terjemahan oleh Sasongko, Erlangga, Jakarta.

Kodoatie, Robert J., 2002, Hidrolika terapan: Aliran pada saluran terbuka dan pipa, Terjemahan oleh Sasongko, Erlangga, Jakarta.

(https://ko2smath06.wordpress.com) Diakses tanggal 12 Februari 2016. 